\title{
Hemorrhage from the point of traction on the opposing wall after colonic endoscopic submucosal dissection using countertraction: a rare adverse event
}

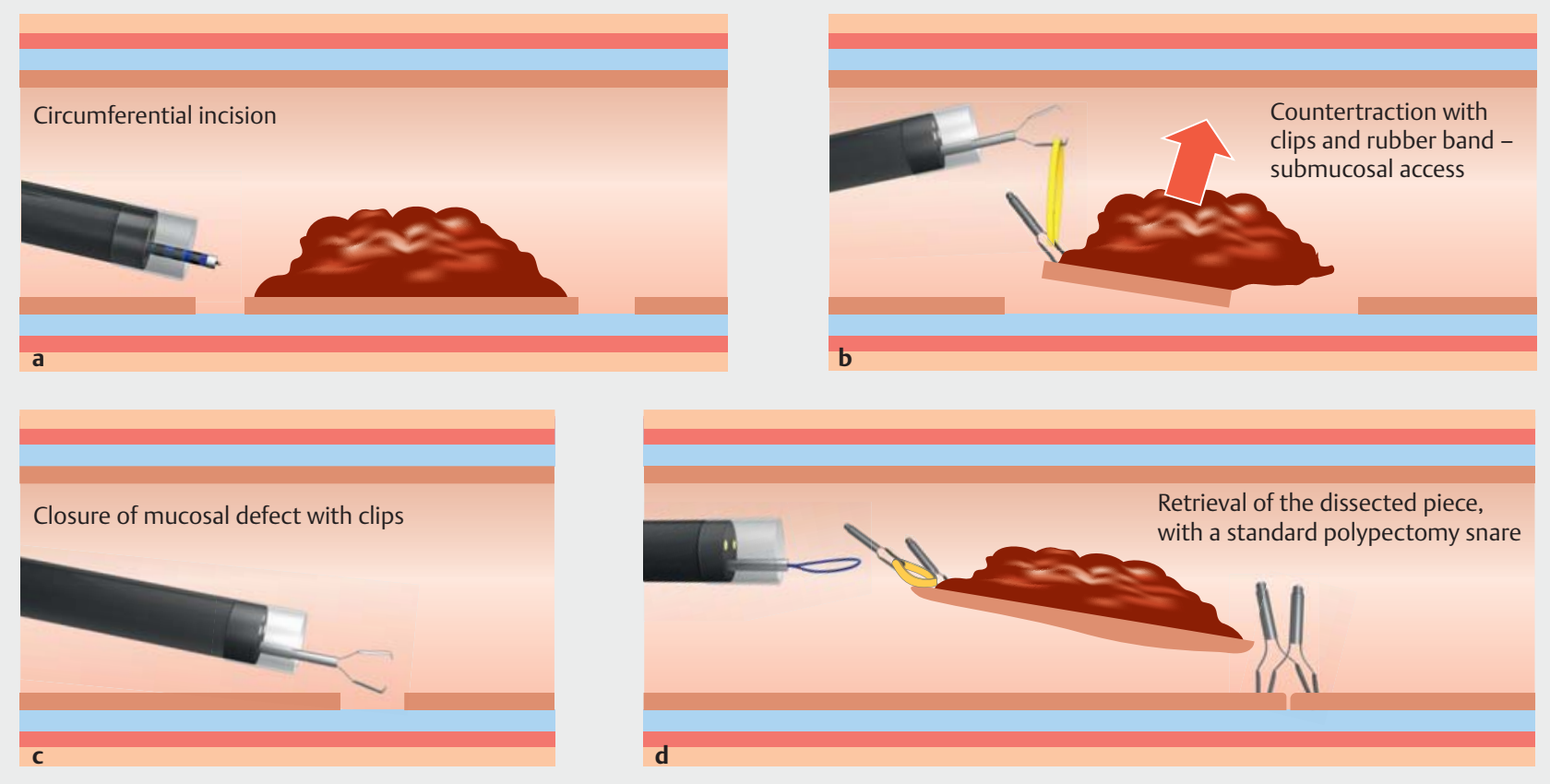

Fig. 1 Schema of the endoscopic procedure showing: a the circumferential incision; $\mathbf{b}$ countertraction with clips and a rubber band; $\mathbf{c}$ closure of the mucosal defect; $\mathbf{d}$ retrieval of the resected specimen.

Endoscopic submucosal dissection (ESD) is recommended for complete en bloc resection of colonic lesions that are larger than $20 \mathrm{~mm}$ and with a high risk of limited submucosal invasion, based on depressed morphology and an irregular or nongranular surface pattern [1]. Recent studies have shown that countertraction techniques using clips and a rubber band increase the $\mathrm{R} 0$ resection rate and significantly decrease the procedure time, while also decreasing the complication rates (perforation and bleeding) [2].

We report here the case of an 87-year-old patient who was on no anticoagulant or antiplatelet treatment and had no prior coagulation disorder. A pseudodepressed nongranular 15-mm laterally spreading tumor (Paris 0-Ila+0-Ilc, Kudo Vn, Sano IIIb, JNET III, NICE III) was found in

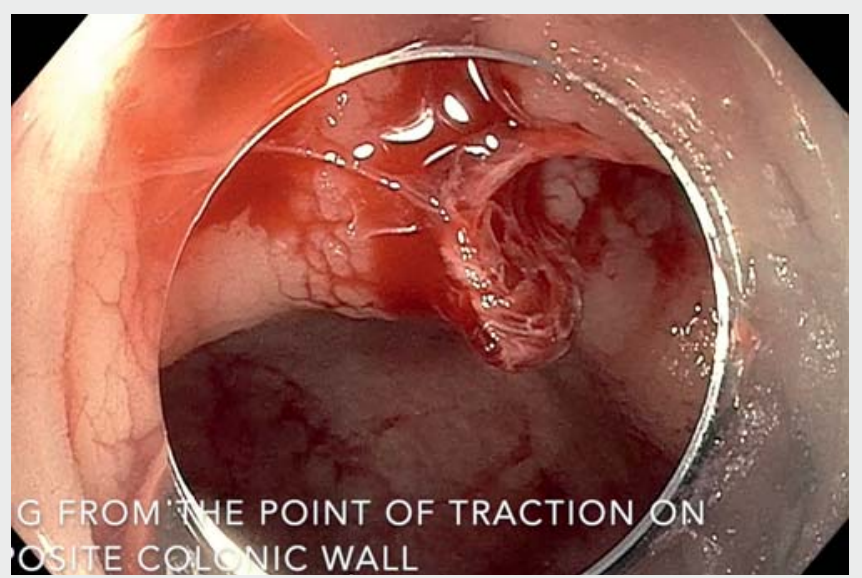

Video 1 Endoscopic submucosal dissection using countertraction is performed for a colonic laterally spreading tumor; bleeding is later identified from the opposite colonic wall and endoscopic hemostasis is achieved. 


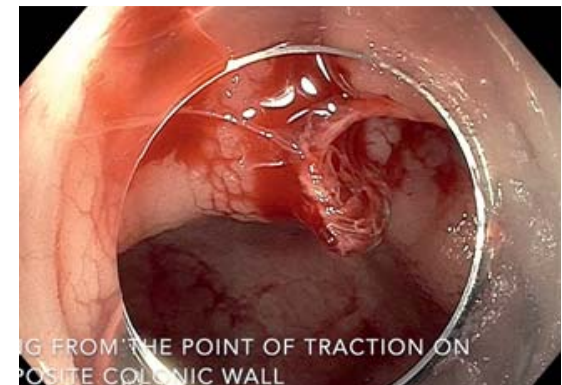

-Fig. 2 Endoscopic view showing bleeding from the opposite colonic wall.

the right colon. Although right hemicolectomy would have been the standard therapy, because of the small size of the lesion and the advanced age of our patient, we decided to perform a diagnostic en bloc resection using ESD with countertraction (-Fig.1). A $30 \times 25-\mathrm{mm}$ piece was retrieved and the dissection scar was closed with three hemostatic clips (Resolution 360; Boston Scientific, USA) ( Video 1).

Several hours after the procedure, the patient presented with significant rectorragia, so a second colonoscopy was performed. Active bleeding was observed from the colonic wall that was opposite to the dissection scar, corresponding to the point where the traction clip had been previously placed ( Fig. 2; - Video 1). Hemostasis was obtained using a hot biopsy forceps (EndoJaw Hot; Olympus, Japan) and two hemostatic clips. The patient was discharged
48 hours later, having experience no other adverse events.

To the best of our knowledge, this is the first report of active bleeding from the opposing normal colonic wall, where a traction clip had been placed. Although very rare, this case highlights the importance of gentle traction on the parietal clip when retrieving the dissection specimen, and careful inspection of the site prior to completion of the procedure.

Endoscopy_UCTN_Code_CPL_1AJ_2AD

Competing interests

The authors declare that they have no conflict of interest.

The authors

Adrien Patenotte ${ }^{1}$, Alexandru Lupu ${ }^{1}$, Jérémie Jacques², Jérôme Rivory ${ }^{1}$, Florian Rostain ${ }^{1}$, Mathieu Pioche ${ }^{1}$

1 Gastroenterology and Endoscopy Department, Edouard Herriot Hospital, Lyon, France

2 Service de Gastroenterologie, Dupuytren Hospital, CHU, Limoges, France

\section{Corresponding author}

\section{Alexandru Lupu, MD}

Edouard Herriot Hospital, 5 PI Arsonval, Lyon 69003, France

alexandru.c.lupu@gmail.com

\section{References}

[1] Pimentel-Nunes P, Dinis-Ribeiro M, Ponchon $T$ et al. Endoscopic sub-mucosal dissection: European Society of Gastrointestinal Endoscopy (ESGE) Guideline. Endoscopy 2015; 47: 829-854

[2] Jacques ], Charissoux A, Bordillon P et al. High proficiency of colonic endoscopic submucosal dissection in Europe thanks to countertraction strategy using a double clip and rubber band. Endosc Int Open 2019; 07: E1166-E1174

\section{Bibliography}

Endoscopy 2021; 53: E279-E280

DOI 10.1055/a-1261-2915

ISSN 0013-726X

published online 1.10 .2020

(c) 2020. Thieme. All rights reserved.

Georg Thieme Verlag KG, Rüdigerstraße 14,

70469 Stuttgart, Germany

\section{ENDOSCOPY E-VIDEOS \\ https://eref.thieme.de/e-videos}

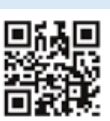

Endoscopy E-Videos is a free access online section, reporting on interesting cases and new

techniques in gastroenterological endoscopy. All papers include a high quality video and all contributions are freely accessible online.

This section has its own submission website at https://mc.manuscriptcentral.com/e-videos 